\title{
Lessons learned in setting up an open access journal: the case of JEHC
}

\author{
Maarten Hogenstijn ${ }^{1 *}$, Marca V.C. Wolfensberger ${ }^{2}$ and Albert Pilot ${ }^{3,}$ \\ 1 Hanze University of Applied Sciences Groningen, the Netherlands; ma.hogenstijn@pl.hanze.nl \\ 2 Hanze University of Applied Sciences Groningen and Utrecht University, the Netherlands; \\ m.v.c.wolfensberger@pl.hanze.nl \\ 3 Utrecht University, the Netherlands; a.pilot@uu.nl \\ * Correspondence: ma.hogenstijn@pl.hanze.nl; Tel.: +31-6-10531652
}

\begin{abstract}
This paper details the lessons learned in the process of setting up a new open access (OA) journal from scratch. The Journal of the European Honors Council (JEHC) was started in 2016, published its first issue in 2017 and is currently publishing its fifth issue. The development of JEHC is described in four phases: lead-up to the first idea (2015-2016), from first idea to first issue (2016-2017), professionalization (2017-2018) and increasing impact (2018-). Ten lessons learnt are detailed: (1) do a realistic needs assessment; (2) involve committed people with skills, passion and time; (3) provide a low-barrier publication option; (4) identify and pick 'low-hanging fruit'; (5) get your basics organized; (6) invest time in technical knowledge; (7) professionalize in phases; (8) be transparent, open and personal; (9) try to avoid monetary transactions as much as possible; and (10) printing can help. The main piece of advice to others wishing to start an OA journal is: inform yourself well before you start, but do not be afraid to learn along the way.
\end{abstract}

Keywords: open access publishing, journal; open access journal; Open Journal Systems; editorial workflow

\section{Introduction}

The Journal of the European Honors Council (JEHC) is a young open access journal, which was started in 2016 and published its first issue in 2017. At the time of writing, it is publishing its fifth issue in total.

Open access publishing is a topic receiving much attention and also a hotly contested issue in both politics and academia. While there is no universally agreed definition of open access, even the most minimal of definitions refer to the notion that research literature should be freely available to read online (Van der Zee \& Reich, 2018; Piwowar et al., 2018). Regarding the prevalence, an analysis shows that $45 \%$ of the articles published in 2015 were openly available (Piwowar et al., 2018). In political discussions, a slow move towards support of open access and the more broadly-defined open science is visible in recent years. However, many involved feel that progress is too slow and therefore in 2018, Plan $S$ was put forward by a coalition of national research agencies and funders from twelve European countries. Its main principle is that "with effect from 2021, all scholarly publications on the results from research funded by public or private grants provided by national, regional and international research councils and funding bodies, must be published in Open Access Journals, on Open Access Platforms, or made immediately available through Open Access Repositories without embargo" (ScienceEurope, 2018). Plan S (where S stands for science, speed, solution or shock) causes much debate in politics, among publishers and in the media. Among scholars, discussions on open science focus both on the ethical aspects and the practical aspects. In a recent piece in the journal Publications, Jon Tennant and 15 other scholars sum up the debate by drawing up a list of ten hot topics to address in scholarly publishing, ranging from the problem of predatory publishers to the monetary side of publishing (Tennant et al., 2019).

This contribution starts from the practice of open science rather than the debate on or theory of open science, by reporting on the lessons learned in the process of setting up an open access (OA) journal from scratch. Setting up JEHC and developing it to its current state has been an eventful process and has brought about insights that may be of benefit to a wider audience involved in OA publishing, in particular those with similar plans to start OA journals or 'flip' existing journals to OA. 
This paper is divided in four sections. After this introduction, we move to a case description of developing the journal in four phases. In the third section, we mention the lessons learned in the process, while in the fourth and final section we discuss the possible broader implications of these lessons.

The authors of this article are coordinating editor (author 1) and Editorial Board members (authors 2 and 3) of JEHC. In addition, author 1 is Secretary and author 2 is President of the European Honors Council, which publishes the journal.

\section{Case description: developing the journal in four phases}

In this section, we describe how the Journal of the European Honors Council (JEHC) was developed; from the context in which the first idea emerged to the situation at the time of writing, with publication of the fifth issue in progress. Interestingly, what turned into the first issue of the Journal, was not initially conceived as a journal at all. Instead, it was intended as a publication of conference proceedings.

We see four phases in the development of JEHC: lead-up to the first idea (2015-2016), from first idea to first issue (2016-2017), professionalization (2017-2018) and increasing impact (2018-).

Phase 1: Lead-up to the first idea (2015-2016)

A first prerequisite for a new journal is a clear gap: a need for a new publication outlet related to a specific subject. JEHC focuses on talent development and honors programs in (European) higher education. This was and still is a relatively new field, in which a lot of developments are taking place and people are looking for information and connections. To understand how the 'gap' for JEHC was found, it is necessary to discuss the subject area of the journal in some more detail. The need for the journal was first made explicit in the research project Honors in Europe. This project was initiated at the Research Centre for Talent Development in Higher Education and Society at Hanze University of Applied Sciences (UAS) Groningen in the Netherlands, with the aim of mapping talent development programs in higher education - which are often called honors programs - around Europe [2]. The first phase of this project consisted of a mapping study carried out in eleven countries. This study was supported by the Sirius Program, a government-funded program running from 2008-2016, aimed at stimulating the development of talent development programs in the Netherlands. The research culminated in the book Talent Development in European Higher Education - Honors programs in the Benelux, Nordic and German-speaking countries (Wolfensberger, 2015), which was published in open access at Springer Open in early 2015. Immediately after publication, the book started to be downloaded in large numbers. In total, it has since been downloaded over 80,000 times. This showed two things: first, that many people were looking for information on the subject; and second, the strength of making information available in open access.

In gathering the data for the research, people from the different countries involved clearly expressed both willingness to share information and interest in making international connections. One of the main conclusions of the book therefore was 'that international networks and national frameworks for honors education are mostly lacking. Focus in education for talented and motivated students is still on compulsory education in many countries. The setup of an international honors network in Europe could give a great boost to education for talented students' (Wolfensberger, 2015, p. 277).

This challenge was subsequently taken up by setting up the European Honors Council (EHC): a new European network around the subject of talent development in European higher education. The idea was floated at an international conference in Nijmegen (the Netherlands) in June 2015. Here, a core group was formed, which spent the academic year 2015-2016 preparing to open the EHC for membership: writing a mission statement, setting up a website, etc. One of the aims of the EHC was formulated as 'creation and exchange of knowledge about honors programs' (European Honors Council, 2016). The EHC made its first presentation to the outside world at the conference 'Honors Futures' in Utrecht, the Netherlands, in June 2016. This was a large conference on honors programs and talent development in higher education, with hundreds of delegates from around the world in attendance. Here, the EHC opened for membership, which was and still is free.

In the run-up to the conference, some of the people involved in the first Board of the EHC were approached by the Utrecht conference organizers to take part in the review process of the contributions to the conference. It was in this process that the first idea of the journal came up. It was felt that the conference yielded a very interesting and diverse set of contributions. An idea to publish some form of conference proceedings was mentioned. While the conference organizers were supportive of the idea, they did not want to pursue this 
themselves. Then the idea came up to make it into a journal, and to use the new organization EHC as publisher of the journal. The EHC Board had already concluded in its mission statement that a clear need was felt to have a publication outlet for new research about honors education and talent development. One and one made two: it was decided that the rich source of possible publications related to the Utrecht conference would be used to create the first issue of the Journal of the European Honors Council.

The argumentation for setting up the Journal was straightforward: it clearly fitted the aims of the EHC and filled a gap, as focused publication outlets on the topic (in Europe) were lacking.

While there are different publications focused on talent development in education, these are mostly focused on programs for gifted children in compulsory education (primary and secondary education). Examples of such journals are High Ability Studies, Gifted Child Quarterly, or Journal for the Education of the Gifted. Research on talent development and honors programs in higher education sometimes ends up in one of these journals. Another publication possibility is formed by journals devoted to higher education in general, such as Higher Education, Journal of Higher Education, Research in Higher Education, Studies in Higher Education or the European Journal of Higher Education. Thirdly, some research is published in journals devoted to education in specific fields. A final publication option is the Journal of the National Collegiate Honors Council (JNCHC), the main scholarly publication outlet of the American organization of undergraduate honors programs. In subject matter, JNCHC is most closely related to JEHC. However, JNCHC is mostly focused on American honors programs, even though it also regularly publishes articles from and to an international audience and has published special issues on Honors around the globe. New issues of the journal are first made available to the NCHC membership and then released to the public through a university repository. Over the years, JNCHC has proved a source of inspiration for scholars in honors education. Still, the need for a dedicated European-based journal in full open access was felt.

The consequence of the diverse range of publication options as described above has been twofold. On the one hand, researchers have often run into the problem that their contribution is considered outside the scope of the journal they send in to. On the other hand, scholars who try to keep up-to-date with developments in the field need to consult a very wide range of journals. A dedicated open access journal on talent development in higher education was still missing in the European context.

Phase 2: From idea to first issue (2016-2017)

Both the President and the Secretary of the European Honors Council were among the group of reviewers for the Utrecht conference where the idea for the journal emerged. They brought the idea to the agenda of the next EHC board meeting. The ten Board members were enthusiastic and approved of the idea, although no budget was available, except for hosting a basic website. Based on the success of the open access availability of the book [3] which was at the basis of the EHC, it was taken for granted that the journal was to be published in open access.

The EHC Secretary then started working to get the basics right and by doing so, assumed the role of coordinating editor. Main tasks were to set up an Editorial Board, decide on the types of contributions for the journal, set up a peer review process, develop a publication template and set up a basic website. Key resources in this process were made available through the Research Center for Talent Development in Higher Education and Society at Hanze University of Applied Sciences Groningen (Hanze). As the aims of the journal matched the aims of the Research Center, the coordinating editor, who works in the Center as senior researcher, could devote time to the development of the journal and draw upon the Center's knowledge, networks and other resources.

The Editorial Board was first set up with four members who had been involved in the peer review process for the Utrecht conference: the EHC Secretary and President, as well as two recently retired experts on honors education: a professor and a senior researcher. From the EHC Board, members from Austria and from Belgium were recruited. A member from Germany was sought, but this took some extra time. One of the organizers of the Utrecht conference was included in the Board as guest editor for this specific issue.

The first discussion in the newly-formed Editorial Board focused on the types of contributions the journal would publish. It was already clear that the journal would publish research papers, but the need for an additional publication format was felt. Among the contributions for the Utrecht conference, a lot of interesting abstracts were found, which focused on good practices or preliminary research results. It was felt that contributions based on these abstracts would be very interesting for the audience involved in talent development and honors in higher education, but was the new journal the right publication outlet? On the one hand, it would provide the 
journal with short accessible pieces that could possibly be of immediate use in education programs, while at the same time providing a relatively low-barrier option to publish. On the other hand, publishing such contributions could 'scare off' researchers wishing to publish full research papers, as it could be felt that the short contributions took some 'prestige' off of publishing in the journal. After some discussion through e-mail and Skype, the Editorial Board decided to offer a low-barrier publication option in the form of 'notes', which were defined as short pieces (up to 1,000 words) reporting on good practices and/or preliminary research results. The notes would be handled by the Editorial Board, with one member made responsible for reviewing the contribution and, if accepted, guiding it towards publication along with the coordinating editor. Full research papers (up to 5,000 words) were to be peer reviewed, with two anonymous reviewers assigned by the coordinating editor.

Once these decisions were taken, a document detailing the editorial process and a publication template were prepared by the coordinating editor. Also, a basic website was set up by the coordinating editor, using a simple html-based template. A journal logo was made, based on the EHC logo. The contributions were to be published in pdf files.

Then the selection process of contributions to the Utrecht conference was set to start. It was hoped that a first round of selection on the basis of abstracts could be finished before the conference. However, this was too optimistic, as the conference was already about to start and there were over 100 abstracts to review. Therefore, it was decided that the selection would be made on the basis of both the abstracts and the presentations at the conference (insofar as the Editorial Board members would be able to see these). The conference was held early June and all Editorial Board members attended and read through all abstracts. This took some time and also led to some discussions regarding the publication potential of specific contributions. It was then decided to send out two kinds of invitations: one to send in a note, and one to send in a paper or a note.

Finally, by late October, decisions were made. Out of the 110 contributions, 25 were invited to send in a note, and another 25 to send in a paper or note. In most cases, the invitation e-mail would include a specific message. Examples of such messages are: 'Please target your contribution at an international audience. It would be great if you could elaborate on the do's and don'ts of your approaches' and 'Please explicitly focus on the students' point of view and evaluate your experience'. In a few cases, authors were asked to team up with other contributors or to merge contributions. The invitations were sent through the Utrecht conference organization, who referred to the e-mail address and the website of the EHC to reply. The people who reported interest to submit for publication received further instructions through the EHC. In total, 20 expressions of interest were received: 11 from among those invited to send in a note; and 9 from those invited to send in a paper or note. In the end, nine out of 11 invited for notes sent in a contribution. From the nine invited for paper or note, five sent in a paper and two sent in a note. The peer review process was done by e-mail, with the coordinating editor as central point of contact for both authors and reviewers.

Finally, the first issue counted 18 contributions in total. The first two were introductions, to the new journal in general and to the special issue about the conference in particular. They were followed by five papers and 11 notes. The contributions were copy edited by the coordinating editor, prepared for publication in pdf format, sent back to the author(s) for verification and finally published on the journal website as pdf.

Interestingly, at no point in the process the idea had come up to charge authors an article processing fee. It was taken for granted that as little money as possible would be involved in the publication of the journal. However, with the first issue nearing completion, the issue of printing came up. It was strongly felt in the Editorial Board that presenting a printed issue would be important for the journal's development. Luckily, a small budget could be secured to publish the first issue not only online, but in print as well. The idea was to attract attention for the new journal among a targeted audience by distributing the printed version among the visitors of the annual international honors conference in the Netherlands in June 2017, a year after the Utrecht conference. To make this possible, a cover for the Journal was designed. The coordinating editor asked a graphic design student to do this for a small fee. In addition, the coordinating editor registered the journal at the National Library of the Netherlands, providing it with ISSNs for both the printed and online versions. The printed version simply consisted of the cover; four pages of front matter including a page with author guidelines, a call for contributions and a list of the Editorial Board members; and the bundled pdf files of the separate articles.

Phase 3: Professionalization (2017-2018) 
By the time the first issue was ready, the second issue was already planned. This second issue was linked to the annual international honors conference in the Netherlands in June 2017, where the first issue was also presented. The organizers of this conference at Windesheim University of Applied Sciences welcomed the idea to collaborate with the journal to publish a special issue related to the conference, and two of the conference organizers joined the Editorial Board. In addition, during the conference room was made for a short official presentation of the journal, handing it over to representatives of American and Chinese honors education organizations. It was also offered to the conference delegates. In addition, the Editorial Board organized a work session on the future direction of the journal. The printed version was well received by the participants of the conference and the work session yielded good ideas on content. Some expressions of interest to publish came in. The number of expressions was more limited than for the Utrecht conference, but this was not considered a great problem by the Editorial Board.

In the process of preparing the second issue, a professionalization process for the journal was also started. A professor from the United States and a researcher from Germany were asked to join the Editorial Board, strengthening the content of the journal. On the technical side, three main goals were set:

1. Get accepted into the Directory of Open Access Journals (DOAJ), as a sign of journal quality;

2. Ensure long-term access by applying a system handling DOI assignment and archiving;

3. Improve the editorial workflow and website.

This all served to make the Journal more professional and less dependent on the person of the coordinating editor, who up to this moment was handling all technical issues regarding the publication process and website.

The three goals proved to be very interrelated. The coordinating editor inquired what was needed to make a successful application for inclusion in the DOAJ, which was perceived as a minimum 'quality mark' for open access publishing (Olijhoek, Mitchell, \& Bjørnshauge, 2015). In fact, some prospective authors mentioned that their institution only allowed them to submit work to OA journals listed in the DOAJ. When looking up the application procedure, main items missing were an archiving policy and a licensing policy. To be able to get policies on this matter in place in a way that would not require manual work by the coordinating editor upon publication of each contribution, it was clear that a system for the editorial process was needed. The coordinating editor went on a search among other open access journals and found out that the ones not tied to a big publisher were often using Open Journal Systems (OJS). This open source system, which already launched its first version in 2002 (see Willinsky, 2005), offers both a system to handle the editorial workflow and a website. Other journals were already published successfully on OJS: both new ones and existing ones that had made the switch (see for example Botsford \& Haggerty, 2010). OJS is developed by the Public Knowledge Project (PKP) as freely available open source software, which in the opinion of the coordinating editor fits well with an open access journal, and in the words of Botsford \& Haggerty 'can mean the difference between existence and non-existence' (2010, p. 9).

After informing himself about OJS, the coordinating editor set up a test environment on his personal webspace. For the installation this required some help from a friend with more technical knowledge. However, once installed it seemed to work well. In a Skype meeting with the Editorial Board the new system was introduced and the Board agreed to test the environment for the publication of the third issue. In the meantime, the second issue was finished through the old system.

The test did show some problems with the automated messages from the system reaching the reviewers, and the automated replies from the system reaching the authors. Still, in general it was felt that the new system was a major improvement and should be implemented. However, the test installation on personal webspace did not solve the problem of the publication process being dependent on the person of the coordinating editor. Therefore, contact was made with the media department at Hanze. Institution-wide decision makers had already shown enthusiasm for the initiative taken in the Research Center for Talent Development in Higher Education and Society at Hanze to publish an open access journal. The question from the coordinating editor was if Hanze would be willing to host the journal and handle technical issues. Soon, it was clear that a decision on this issue would take some time. The third issue was therefore finally published through the old system.

After taking some time to consider the request and consulting the IT department, the Hanze media department managed to secure some funding from the institution to host the journal as a pilot project in open access publishing. An important factor in this consideration was the fact that Hanze was in the process of 
developing a new open science policy for the whole institution. One additional piece of support by Hanze was the provision of Digital Object Identifiers (DOIs). Hanze decided to become a member of Crossref and received its own prefix for the allocation of DOIs, which could be used by the Journal.

The media department at Hanze finally decided not to host the journal itself, but to buy a hosted solution from PKP, the developers of OJS. By July 2018, the installation was complete, including an option to automatically assign DOIs to newly published articles. Also, automatic archiving was secured through the hosted solution and the registration at the National Library of the Netherlands. This meant that the fourth issue of the journal could be completely handled through the new system, which provides much more clarity about the editorial workflow for authors, reviewers and Editorial Board members; as well as a much better-looking website.

In addition, the installation of OJS meant that everything was in place for an application to the Directory of Open Access Journals (DOAJ). This was also delivered in July 2018. With the application to DOAJ under consideration, the 'back catalogue' of the journal, consisting of the first three issues, required some work. These issues had to be placed in the new editorial system and website, and they needed to have DOIs assigned. The deliberate choice was made not to assign DOIs for the articles in these issues before, as the implementation of OJS was in progress. Assigning DOIs to the back catalogue had to be handled manually, requiring a one-off time investment by the coordinating editor. In October 2018 this process was finished, and all authors of contributions in the first three issues were informed that a DOI had been assigned to their article; and they were asked to refer to these DOIs from then on.

\section{Phase 4: Increasing impact (2018-)}

By autumn 2018, the three main goals of the professionalization phase were reached. The new website was up and running and the editorial process for the fourth issue was handled completely through Open Journal Systems. The USA-based Editorial Board member had been able to set up copy editing by a native speaker, significantly improving the contents of the journal. On the technical side, DOI assignment and archiving were integrated into the editorial system through OJS. In September 2018, JEHC received the message that it was accepted into the Directory of Open Access Journals.

This meant that a new phase started for JEHC, where attention shifted to increasing the impact of the journal. The Journal was already indexed by Google Scholar. The introduction of DOls and the use of OJS made it easier to see statistics on article level. However, getting representative statistics still proved difficult. The 'back catalogue' remained available on the old journal website, and articles had been and are continually being placed in scholarly social network sites such as ResearchGate, as well as repositories on institutional and (inter)national levels. While this increases the chances of making impact with the journal contents, at the same time it is harder to keep track of the impact that is generated. Indications are that total numbers of downloads per article are in the hundreds rather than thousands.

Therefore, the new phase shifts focus towards developing new ideas on 'journal marketing'. This includes widening the pool of potential authors and further developing special issues on topical issues in honors education and talent development. It is felt in the Editorial Board that special issues are a good way to specifically target both potential authors and readers, while at the same time there should also always be room for articles not directly relating to the subject of the special issue, but to the journal subject in general.

The fourth issue was a special issue on good practices in honors education and was finally published in January 2019. At the time of writing, publication of a fifth issue without a specific theme is underway, and a call is out for contributions to the sixth issue. This will be a special issue on 'honors education in the digital age' and is set to be published in January 2020 .

\section{Lessons learned}

The process of setting up JEHC was eventful. Some things went well, but mistakes were also made. The ten main lessons learned in the process are detailed below.

1. Do a realistic needs assessment

Before starting a journal, a clear idea is needed in relation to the question of added value. Are there enough potential readers for the new journal, and are there enough scholars willing to publish? In the case of JEHC, we did not do specific research into this, but the need for a journal focusing on honors and talent development in higher education had already become clear through the research project Honors in Europe, for which contacts 
were made with over 300 higher education institutions in 11 European countries, and in the set-up process of the European Honors Council. We felt that there would be enough potential readers among this group. We could have given more thought to the potential authors. As the first two issues were set up in relation to existing conferences, this was not an urgent point. However, it became clear in the preparation of the third and following issues that spontaneous contributions to the journal still remained relatively rare. The issue of journal marketing could have been taken up more seriously earlier in the process.

2. Involve committed people with skills, passion and time

Setting up a journal requires skills, passion and time. While a lot of the skills can be developed along the way, key people for the journal need to be able to work together constructively and see the fun in developing a new publication outlet. A dedicated team of Editorial Board members with complementing skills and a passion for the journal subject is crucial. Then, a sense of community can develop, in which people help each other to overcome the problems in technical and other areas which a new journal undoubtedly encounters. In the case of JEHC, committed people with complementing skills were found. It certainly helped that the coordinating editor (author 1) has a background in journalism and editing. The President of the European Honors Council, who is also the professor heading the Research Center for Talent Development in Higher Education and Society (author 2) brought in the knowledge and resources of her Center, her extensive networks and experience with a wide range of publications. In addition, it was very helpful that two recently retired dedicated experts (a professor - author 3 - and a senior researcher) agreed to join the Editorial Board. They were willing and able to invest time in the journal, provide input and feedback on both content and editorial procedures, and were well-connected with possible authors. Their efforts and experience proved very helpful in setting up the journal. The other Editorial Board members each added their own useful input. In the starting phase in particular, people need time to discuss about the basics of the journal, and to process the first contributions. Editorial Board members were willing to devote this time outside regular working hours.

\section{Provide a low-barrier publication option}

In the case of JEHC, a clear need for sharing good practices and preliminary research results was identified. To provide for this need, we established the contribution type of 'notes'. This turns out to be a popular type. In the four complete issues published at the time of writing, 3 out of every 4 contributions turn out to be notes (see table 1).

Table 1. JEHC types of contributions per issue

\begin{tabular}{cccc}
\hline Issue & Papers & Notes $^{1}$ & Total \\
\hline Vol 1, issue 1 & 5 & 13 & 18 \\
Vol 1, issue 2 & 2 & 6 & 8 \\
Vol 2, issue 1 & 3 & 4 & 7 \\
Vol 3, issue 1 & 1 & 10 & 11 \\
Total & 11 & 33 & 44 \\
\hline
\end{tabular}

${ }^{1}$ Issue introductions are published as notes and included here.

When setting up the journal, the first subject discussed in the Editorial Board was whether the introduction of 'notes' would scare off authors wishing to publish full papers in a prestigious journal. It is still not entirely clear if this is the case, but it is possible, seeing the relatively small number of full papers. We recommend publication formats to be a subject for serious and early consideration when setting up a new OA journal.

4. Identify and pick 'low-hanging fruit'

In many fields, there is a possibility to link publications to events such as conferences. In the case of JEHC, a deal was made with the current and future organizers of an annual international conference on honors education in the Netherlands, enabling the journal editors to get in touch with people submitting contributions to the conference to consider submitting for the journal as well. This proved a great way to get in touch with authors with promising contributions and invite them to submit to the Journal. 


\section{Get your basics organized}

While in our experience you do not need a perfectly organized journal before you start (see lesson 7), it is essential to get a number of basics organized before the publication process starts. This includes a good description of the scope of the journal, having a (basic) Editorial Board, as well as a description of the review and publication processes and licensing info (see 6). This is needed to provide clarity to all involved: potential authors, but also your Editorial Board. Also, you need someone to take up the role of coordinating editor or Editor-inChief, as main contact point for both authors and Editorial Board members.

6. Invest (some) time in technical knowledge.

Involving a person with some technical knowledge is essential when setting up an open access journal. This includes knowledge on the technical details of the editorial process, as well as about hosting and licensing. If this knowledge is not available in the Board itself, help could be sought with the libraries of institutions to which Editorial Board members are attached. As these are often supportive of initiatives in open access publishing, they could provide valuable information and possibly resources. In the case of JEHC, we relied mainly on the technical knowledge of the coordinating editor in phases 1 and 2, and then on the additional technical knowledge at Hanze in phase 3. Looking back, this help could have been sought earlier in the process. One basic piece of technical information we clearly missed was knowledge about licensing. While the Editorial Board was clear that we wanted to publish our journal in full open access, none of the members were really familiar with the licensing involved. Therefore, in our first two volumes, we did communicate to authors and in the journal front matter that the publication was in full open access, but we did not include any licensing info in the articles published. When we entered the phase of professionalization, we corrected this and started publishing under a CC-BY license. This was also clearly indicated to authors on the journal website and in the submission process, as well as in the pdf file of every single article.

\section{Professionalize in phases}

One main lesson for others wishing to set up an OA journal is that, in our experience, it is not necessary to wait until everything is set up perfectly (see also 5). In addition, it is possible to change rules and procedures as you progress into publication of next issues. For example: initially we said that 'notes' in JEHC should count a maximum of 1,000 words. When preparing the first issue, it soon turned out that this was too tight and maximum note length for the next issue was set at 1,500 words. Again, this proved tight for some contributors, who said they had to make compromises on quality due to the word limit. Discussion in the Editorial Board resulted in a clear focus on quality over word count. Therefore, currently, a maximum of 1,500 words is suggested but not strictly applied. The same goes for papers - the maximum of 5,000 words is now also suggested.

At the time of writing, the Journal is starting a new professionalization phase, now with regards to what could be called 'journal marketing'. While it would have been useful to have focused on this earlier, priorities had to be set because of limited time and the choice to delay this is still supported in the Editorial Board.

\section{Be transparent, open and personal}

When you set up a new journal, others will usually understand that not everything is running perfectly from the start. Transparency is key in this. We recommend to make it clear to (potential) editors, contributors and readers that your journal is new and that you are open to suggestions for improvement. In our experience, this helps in getting people into a mindset where they are not mere 'customers' or consumers of articles, but where they actually help co-create the journal. One important aspect in this is personal communication. It helps if you use personal(ized) messages as much as possible, so contributors understand that the journal is prepared by dedicated people.

9. Try to avoid monetary transactions as much as possible

In the case of JEHC, basically no money was available at the start of the journal. The initial decision was taken not to charge authors article publication fees. Also, none of the Editorial Board members would receive compensation of any kind. In fact, the coordinating editor invested a tiny bit of his own money to claim a url and start a website for the journal (which was later reimbursed by the employer). In our experience, the fact that it is clear that you are not 'in it for the money' provides you with goodwill with your audience of both potential 
authors and readers. In the JEHC case, Hanze (the institution where the EHC secretariat is hosted and where the coordinating editor is employed) was willing to provide hosting and technical support. The Research Center allowed the coordinating editor to put in some work hours and provided an important network for both feedback on content and support on practical issues. It also helped to secure a small budget to print the first three issues. Cost models of OA journals are a much-debated topic. However, the very limited dealing with money at JEHC is in line with practices at some other OA journals. For example, the Journal of Open Source Software recently published a blog explaining in detail their cost model for running an online open journal (Katz, Barba, Niemeyer, \& Smith, 2019). Still, JEHC does not have a structural budget.

\section{Printing can help}

While scholarly publishing takes place in an online world, we did find that having a printed version of the journal was helpful in both getting more attention for the journal and in being taken seriously by some important people. The first issue was printed and handed out officially at the international conference at Windesheim UAS, which formed the basis for the contents of the second issue. The second and third issues were also printed and handed out at an international conference in the next year. In these cases, the (acting) President of the EHC handed over the Journal to the Director / Rector of the institution hosting the conference, creating an official moment attracting attention. This would have been more difficult to achieve without a physical (printed) journal. The future in print for JEHC is still subject to debate in the Editorial Board. As the journal does not have a structural budget (see 9), the money needed for printing has to be found for every single issue. While this is not very practical, one advantage of this process is that the decision to print is taken very consciously, with a clear idea in mind about the added value of printing this specific issue.

\section{Discussion}

Setting up an open access journal from scratch is not easy. However, the difficulties you undoubtedly encounter in the process should also not be overestimated and it is very rewarding to see results.

By reporting on the process of setting up the Journal of the European Honors Council (JEHC), we aim to inspire others to do the same. We share the lessons we have learned, which boil down to a main piece of advice: inform yourself well before you start, but do not be afraid to learn along the way. It is important to note that open access publishing generally implies an open, positive and supportive atmosphere. Many librarians and technicians are wiling to help and there is often goodwill among prospective authors and readers. This makes setting up a new open access journal a process in which there is much to learn in a positive atmosphere, with fun to be had along the way.

In addition, it can be a very inspiring process in a broader sense. Being involved in the practice of open access publishing can help to show its added value, bringing new arguments to open science-related debates that are sometimes in danger of remaining relatively abstract.

For those aiming to start their own OA journal, it would be useful to have more case studies available of initiatives that have or have not been successful. Combining such case studies, an analysis could be made of both the common elements perceived as success factors and the elements that are specific to the field addressed by the journal.

Acknowledgments: Hanze UAS kindly offers administrative and technical support in hosting the new JEHC website and editorial system on Open Journal Systems. The authors acknowledge the work that their fellow Editorial Board members Pierre van Eijl, Marleen Eyckmans, Astrid Fritz, Beata Jones, Tineke Kingma, David Rott, Lineke Stobbe, and former member Annelies Riteco have put into the journal and additionally wish to thank Anouska Jaspersen for the logo design, Steyn van Scheppingen for the journal cover design and Saffyre Falkenberg for copy editing for the journal.

\section{References}

Botsford, L. C., \& Haggerty, K. D. (2010). Using Open Journal Systems to Move from Paper Production to Online Open Access. Scholarly and Research Communication, 1(1): 010301, 12 pp. 
European Honors Council. Aims. Available online: www.honorscouncil.eu/aims.html (accessed on 11 June 2019)

Honors in Europe. Available online: www.honorsineurope.com (accessed on 11 June 2019)

Katz, D.S., Barba, L.A., Niemeyer, K.E., Smith, A.M. (2019, 4 June). Cost models for running an online open journal. Blog. http://blog.joss.theoj.org/2019/06/cost-models-for-running-an-online-open-journal

Olijhoek, T.; Mitchell, D.; Bjørnshauge, L. Criteria for open access and publishing. ScienceOpen Research, 2015. DOI: 10.14293/S2199-1006.1.SOR-EDU.AMHUHV.v1

Piwowar, H., Priem, J., Larivière, V., Alperin, J. P., Matthias, L., Norlander, B., ... \& Haustein, S. (2018). The state of OA: a largescale analysis of the prevalence and impact of Open Access articles. PeerJ, 6, e4375. https://doi.org/10.7717/peerj.4375

ScienceEurope. (2018). What is cOALition S? https://www.coalition-s.org/about/

Tennant, J.P.; Crane, H.; Crick, T.; Davila, J.; Enkhbayar, A.; Havemann, J.; Kramer, B.; Martin, R.; Masuzzo, P.; Nobes, A.; Rice, C.; Rivera-López, B.; Ross-Hellauer, T.; Sattler, S.; Thacker, P.D.; Vanholsbeeck, M. Ten Hot Topics around Scholarly Publishing. Publications 2019, 7, 34; doi:10.3390/publications7020034

Willinsky, J. (2005). Open journal systems: An example of open source software for journal management and publishing. $\begin{array}{llll}\text { Library hi } & \text { tech, 23(4), } & 504-519 .\end{array}$ http://citeseerx.ist.psu.edu/viewdoc/download?doi=10.1.1.473.4565\&rep=rep1\&type=pdf

Wolfensberger, M.V.C. Talent development in European higher education: Honors programs in the Benelux, Nordic and German-speaking Countries. Springer Open, 2015. https://doi.org/10.1007/978-3-319-12919-8

van der Zee, T., \& Reich, J. (2018). Open Education Science. AERA Open. https://doi.org/10.1177/2332858418787466 